\title{
CONTEST OF WEB-BASED GEOSPATIAL APPLICATIONS FOR STUDENTS AND YOUNG SCIENTISTS
}

\author{
F. Tsai ${ }^{\mathrm{a} *}$ and K. Cho ${ }^{\mathrm{b}}$ \\ ${ }^{a}$ Center for Space and Remote Sensing Research, National Central University, \\ 300 Zhongda Road, Zhongli Taoyuan 320, Taiwan \\ ftsai@ csrsr.ncu.edu.tw \\ ${ }^{\mathrm{b}}$ Research and Information Center, Tokai University, \\ 2-28-4, Tomigaya, Shibuya-ku, Tokyo, 151-0063, Japan \\ kohei.cho@tokai-u.jp
}

KEY WORDS: WEBCON, Web-GIS, web contest, promotion to young people, internet-based application

\begin{abstract}
:
The Asian Association on Remote Sensing (AARS) organizes a web contest (WEBCON) of photogrammetry, remote sensing and spatial information sciences in the annual meeting of Asian Conference on Remote Sensing (ACRS) every year. The purpose of WEBCON is to promote the development of web and other forms of internet services of the internet related to geo-information sciences and to attract more students and young scientists participating in the related fields of study and applications. Since 2011, WEBCON has become one of the major events in ACRS and successfully increased the interest in the research, development and applications of photogrammetry, remote sensing and spatial information sciences among students and young scientist. The success of WEBCON is an excellent example of promoting the profession of spatial information to young people.
\end{abstract}

\section{INTRODUCTION}

Google Maps, Google Earth and other Web geographic information systems or internet-based virtual globes provide the public easy access to satellite and aerial images and other geo-spatial information of any place around the world. This type of geographic information platform and service has significantly increased the awareness, publicity, and usability of geo-spatial data and their applications. By providing internet-based web-embedded or standalone systems for representing and visualizing geo-spatial and other data in specific mark-up languages (Ballagh et al., 2011), these systems also enables developers to implement elaborative and fancy interfaces for their sophisticated applications (Sheppard and Cizek, 2009; Wu et al., 2011). As discussed in a previous study (Goodchild, 2008), the use of digital contents of geospatial information is diversified and can be interpreted in very different spatial concepts. In a dramatic way, these technologies have turned the "world-wide-web" into a revolutionary "webwide world" (Butler, 2006).

In academic, the concept of virtual globe has also been rapidly adopted as an effective teaching platform or tool in different disciplines (Goodchild, 2006; Patterson, 2007). In addition, efforts have also been put into the research and development of utilizing these new platforms for assorted applications in different fields. Although vaporwares are not uncommon in the information industry, the nature of web-GIS and virtual globe types geospatial systems has seemed to make them easy to adopt and gain a solid user base among technical and non-technical people (Butler, 2006; Miller, 2006), in particular, students and young scientists since these new generations are more eager to try and accept new concepts and technologies.

However, a commonly criticized weakness of these virtual globe systems is that they seem to be (utilized) just as "geo-browsers" for presenting, visualizing, or exploiting a variety of geo-spatial data sets (Yu and Gong, 2012) with limited functionalities. In addition, as the development of Google Earth API has been put into abeyance and its support is discontinued in the spring of 2016, an obvious question is "What comes next?" or "What can we do to keep up the good trend?"

\section{WEBCON}

In order to promote students and young scientists activities as well as to increase their participation in incorporating new technologies into the research and development of next generation geo-spatial applications and services, the Asian Association on Remote Sensing (AARS), in cooperation with a few ISPRS working groups (WG-VI/1, $2 \& 5$ ), has been organizing a web contest (WEBCON) of photogrammetry, remote sensing and spatial information sciences in the annual meeting of Asian Conference on Remote Sensing (ACRS) since 2011. The primary objective of the contest is two-fold. First of all, it aims to promote the development of web (and later extended to other forms of internet services) materials which may give us a future vision of the internet related to spatial information sciences. Secondly, it is expected that the activity will attract more students and young scientists participating in the field of photogrammetry, remote sensing and spatial information sciences, whether in academic researches, industrial and enterprise practices, or general applications. Therefore, the contest is open to students and young scientists and professionals under age of 35 who are registered to ACRS.

Interested students and young scientists formed teams to participate in the WEBCON. A team typically consisted of one to three individuals. Each team needs to submit a written proposal of their "project" (along with supporting multimedia materials) and implement a working web site and/or client software or Apps. In addition to the basic information of the team members, the proposal typically includes the following items:

1. Title of the project.

2. Design concept and objective.

3. Outline of the web material: brief description of system requirement, framework, scheme or functions. 


\section{URL of implemented homepage}

5. Other information

In the WEBCON special session of ACRS, each team is given 20 minutes to present their web contents and results (including brief live or recorded demonstration). Then an interactive session is held for all teams to demonstrate their systems and works to and discuss with the audience in details. Each year, two to three prizes donated by sponsors were awarded to the best teams of the contest selected by an evaluating committee. The judges evaluate the works according to the following criteria (not necessarily in that order):

\section{- Originality}

- General utility and importance of output

- Scalability and elegance of design

- Clarity, efficiency and portability of implementation

\section{ACHIEVEMENTS}

Since its inception, dozens of individuals or teams have participated in the ACRS WEBCON from 2011 to 2015. The event also attracts more than 100 audience every year. Apart from coming from different countries and institutes, the background of the participanting teams are also diversified, covering a wide range of disciplines. The topics presented by the participating teams comprise different aspects of geo-spatial information sciences and their applications and services. Summarizing the five WEBCON presentations and results, a few important findings are described below.

The contents of the presented materials follow the most advanced trends of photogrammetry, remote sensing and spatial information sciences development. However, their topics and characteristics were diversified. For example, the gold award of the first WEBCON (in ACRS2011) was an online application system of ionosphere model for single-frequency GPS positioning (Tsai et al., 2013), while the gold award of the latest WEBCON5 (in ACRS2015) was a web system to help complete homework (graphic diary) during summer break for elementary school students in Japan. The former involves in the web-based implementation of a developed complex GPS positioning algorithm; the later requires online operation of geo-tag information retrieval, image analysis (pattern and content recognition), and templatebased document generation.

In general, most of the presented WEBCON projects were application oriented. In terms of fields (discipline) of applications, environment-related fields seems to be the most presented topics. However, there were also topics and applications related to social sciences. For example, a web-based online panoramic system for digital cultural heritage applications was presented and won the silver award in WEBCON4 (in ACRS2014).

Most of the presented projects implemented two-dimensional (2D) or three-dimensional (3D) web interfaces. For example, Figure-1 displays the interfaces of a mining web map and a multi-temporal 3D campus modeling system presented in WEBCON2 (in ACRS2012). However, as the ICT (Information and Communications Technology) evolves, the style and format of the presented contests has also extended from conventional web-based presentation and data exploration to sophisticated on-line spatial applications and services. In recent years, Apps for mobile devices have seem to become a "must-have" feature of the presented WEBCON projects.

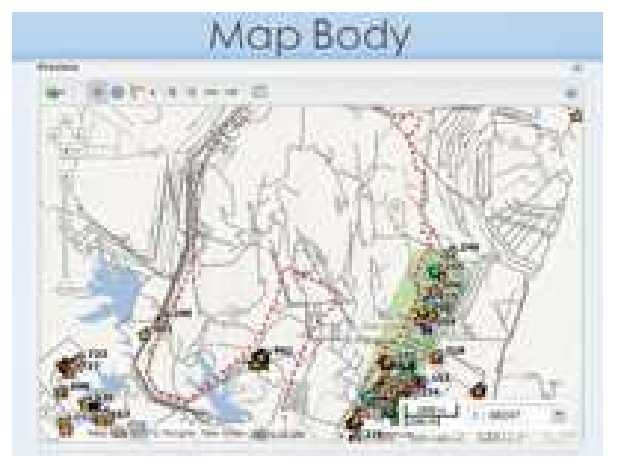

(a) 2D web map (from S. Homhuan, K. Phetrungnapha, W. Chalaruk, 2012, Thailand Mae Moh Mine "Map Web Apps", in WEBCON2)

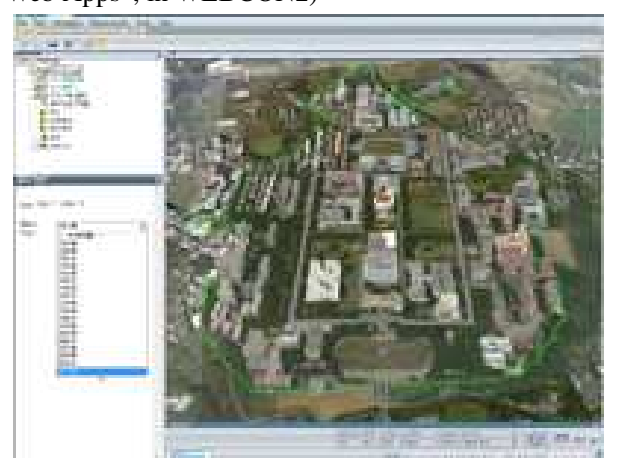

(b) 3D web (from C. Lo, 2012, Historical Representation of Multi-temporal NCU using Three-Dimensional Building Models, in WEBCON2)

Figure 1: Two-dimensional (a) and three-dimensional (b) web interfaces.

\section{CONCLUSION}

In order to promote new geo-spatial technologies to the students and young scientists, AARS (in cooperation with ISPRS WG$\mathrm{VI} / 1,2$ \& 5) organizes a web contest (WEBCON) in the Asian Conference on Remote Sensing (ACRS) since 2011. The contest has established its reputation as one of the major events in ACRS. More importantly, the event has successfully increased the interest in the research, development, and applications of photogrammetry, remote sensing and spatial information sciences to students and young scientists and professionals. Based on the current achievements, future WEBCON will continue to encourage "makers" of the " $3 S$ " technologies and bridge them with advanced ICT and domain knowledges. The success of WEBCON is an excellent example of promoting the profession of spatial information to young people. It is expected that the WEBCON will be a continuing success in ACRS and encourage more students and young scientists to enter related disciplines of photogrammetry, remote sensing and spatial information sciences in the next generations.

\section{References}

Ballagh, L. M., Raup, B. P., Duerr, R. E., Khalsa, S. J. S., Helm, C., Fowler, D. and Gupte, A., 2011. Representing scientific data sets in KML: Methods and challenges. Computers and Geosciences 37(1), pp. 57-64.

Butler, D., 2006. Virtual globes: The web-wide world. Nature 439, pp. 776-778.

Goodchild, M. F., 2006. The fourth r: rethinking GIS education. ArcNews 28(3), pp. 1. 
Goodchild, M. F., 2008. The use cases of digital earth. International Journal of Digital Earth 1(1), pp. 31-42.

Miller, C. C., 2006. A beast in the field: The Google Maps mashup as GIS/2. Cartographica 41(3), pp. 187-199.

Patterson, T. C., 2007. Google Earth as a (not just) geography education tool. Journal of Geography 106(4), pp. 145-152.

Sheppard, S. R. J. and Cizek, P., 2009. The ethics of Google Earth: Crossing thresholds from spatial data to landscape visualisation. Journal of Environmental Management 90(6), pp. 2102-2117.
Tsai, L.-C., Wu, J. and Liu, C.-H., 2013. Application of the TaiWan ionospheric model to single-frequency ionospheric delay corrections for GPS positioning. GPS Solutions 17(3), pp. 337-346.

Wu, H., He, Z. and Gong, J., 2011. A virtual globe-based 3d visualization and interactive framework for public participation in urban planning processes. Computers, Environment and Urban Systems 34(4), pp. 291-298.

Yu, L. and Gong, P., 2012. Google earth as a virtual globe tool for earth science applications at the global scale: progress and perspectives. International Journal of Remote Sensing 33(12), pp. 3966-3986. 